

CHALMERS

UNIVERSITY OF TECHNOLOGY

\title{
Stabilization of herring (Clupea harengus) by-products against lipid oxidation by rinsing and incubation with antioxidant solutions
}

Downloaded from: https://research.chalmers.se, 2023-04-26 14:44 UTC

Citation for the original published paper (version of record):

Wu, H., Ghirmai, S., Undeland, I. (2020). Stabilization of herring (Clupea harengus) by-products against lipid oxidation by rinsing and incubation with antioxidant solutions. Food Chemistry, 316.

http://dx.doi.org/10.1016/j.foodchem.2020.126337

N.B. When citing this work, cite the original published paper. 

rinsing and incubation with antioxidant solutions

3

Department of Biology and Biological Engineering-Food and Nutrition Science, Chalmers University of Technology, SE 412 96, Gothenburg, Sweden

Abbreviated running title: Stabilization of herring by-products against lipid oxidation

*Corresponding author: Haizhou Wu

Tel: +46765626793

Email: haizhou@chalmers.se 
The content of hemoglobin $(\mathrm{Hb})$ in different parts of herring (Clupea harengus) by-products, and three strategies for preventing lipid oxidation during their storage on ice were studied: (i) rinsing away $\mathrm{Hb}$ with water or $0.9 \% \mathrm{NaCl}$ with/without antioxidants (Duralox-MANC, erythorbate and EDTA), (ii) incubation in water/0.9\% 
Fish makes up $17 \%$ of the intake of animal proteins globally, in some coastal countries more than $50 \%$ (FAO, 2014). The fish demand is steadily increasing in response to dietary recommendations and population growth. However, wild fisheries cannot expand further based on endurance of ecosystems and climate changes, and the expected aquaculture expansions will not cover the demand (Alexandratos \& Bruinsma, 2012). One way of increasing the supply of fish products without increasing its environmental impacts is to use the landings of fish more efficiently. This would involve better utilization of e.g. filleting by-products for food production. However, the majority of all by-products from the fish industry are still mainly targeted feed production or waste. Globally, it can be estimated that these raw materials carry around 25 million tonnes of muscle rich in protein and long chained (LC) n-3 polyunsaturated fatty acids (PUFA) (FAO, 2014), which instead could be used in food production to meet the growing seafood demand. The largest potential with fish filleting by-products in food production, lies in producing minces, fish oil, functional protein isolates and protein hydrolysates. Innovative techniques for such productions today exist. For example, Hultin and Kelleher (1999) first developed the $\mathrm{pH}$-shift process for muscle-based raw materials, and it has been successfully recognized as a promising technique for lipid and protein recovery from unconventional complex aquatic raw materials (Abdollahi \& Undeland, 2019; P. K. Vareltzis \& Undeland, 2012). Other existing techniques are classic meat-bone separation (Zhong, Liu, Cao, Chen, Wang, \& Qin, 2016), or enzymatic hydrolysis 

prevent a "take-off" for their implementation is fast oxidative destruction of the valuable LC n-3 PUFA, causing rancidity in the by-products already within hours after the filleting operation (Rustad, 2003), and thus, limiting their chances of staying within the food chain.

Blood and its hemoglobin $(\mathrm{Hb})$ have been revealed as the major components responsible for lipid oxidation in fish (Richards \& Hultin, 2002; Undeland, Kristinsson, \& Hultin, 2004). Fish filleting by-products are all very blood-rich, caused e.g. by gills, caudial vein and the bleeding/injury caused by the actual cutting operation. We therefore hereby state that blood and blood contamination is the main hurdle preventing full utilization of fish by-products for food production. Richards et al. (1998) and Undeland et al.(1998; 2003) rinsed mackerel fillets, herring mince, and cod mince respectively, with water or $50 \mathrm{mM} \mathrm{NaCl}$ solution to remove $\mathrm{Hb} /$ blood prior to storage on ice or in freezer. However, it was found that endogenous hydrophilic antioxidants were removed in such washes which lead to a higher susceptibility of the washed muscle tissue towards oxidation. One potential way to compensate for such loss is by rinsing with an antioxidant solution. Previously, different naturally occurring antioxidants have been used to improve the oxidative stability in minced fish fillets. The addition of white grape dietary fiber (Sánchez-Alonso, Borderías, Larsson, \& Undeland, 2007), caffeic acid (Larsson \& Undeland, 2010) and cranberry extract (C. Lee, Krueger, Reed, \& Richards, 2006) successfully inhibited lipid oxidation in washed fish models or fish mince. However, to the best of our knowledge, there is 
no literature on treating fish by-products with anti-oxidant containing solutions as ways to prevent lipid oxidation, and thereby allowing for their further upgrading to foods or food ingredients.

The aims of this study were to: (i) quantify $\mathrm{Hb}$ in different parts of herring by-products, (ii) investigate whether $\mathrm{Hb}$ was located on the surface or interior in the by-products, and (iii), investigate the effect of rinsing or incubating herring by-products in different solutions on the removal of $\mathrm{Hb}$ and the development of lipid oxidation during subsequent ice storage.

\section{Materials and Methods}

\subsection{Fish samples preparation}

Herring (Clupea harengus) was caught off the west coast of Sweden from September to December of 2018. Fresh herring filleting by-products (head, backbone with caudal fin and residuals (including intestines, skin and fish egg)) were provided by Scandic Pelagic AB (Ellös, Sweden). The post mortem age of herring by-products when arriving in our laboratory were between 1 and 2 days; however, the time elapsing between filleting of the herring, and receival of the by-products was only 2-6 h. The by-products were kept below $5{ }^{\circ} \mathrm{C}$ during the transportation.

\subsection{Preparation of treatment solutions}

The treatment solutions used in rinsing trials were 1) tap water, 2) $0.9 \% \mathrm{NaCl}, 3) 5 \%$ Duralox MANC-213 (Kalsec, Kalamazoo, Mich., UK), 4) isoascorbic acid (0.2\%) + EDTA (0.044\%). The incubation solutions were: 1) tap water, 2) $0.9 \% \mathrm{NaCl}, 3) 1 \%$ Duralox MANC-213, 4) 0.5\% Duralox MANC-213, 5) sodium phosphate buffer (50 mM, pH 7.5), 
5) sodium phosphate buffer $(50 \mathrm{mM}, \mathrm{pH} 6.5)$ 6) $2 \%$ isoascorbic acid. All treatment solutions were freshly prepared from tap water and kept in a cold room $\left(4^{\circ} \mathrm{C}\right)$ at least 5 hours before use.

\subsection{Rinsing of herring by-products with different solutions}

One kilogram of fresh herring by-products were rinsed/shortly incubated in the above treatment solutions (1:5 weight/volume) for $20 \mathrm{~min}$ in cold room $\left(4{ }^{\circ} \mathrm{C}\right)$. Thereafter, the herring by-products were removed from the solutions and drained well in a stainless steel fine strainer. The control samples were not rinsed into any of the solutions. Drained samples and controls were then immediately ground using a table top meat grinder (C/E22 N, Minerva Omega group, Italy) equipped with a plate with $4.5 \mathrm{~mm}$ holes, and thereafter stirred to complete homogeneity. The minces were ice stored according to the method of Larson et al.(2007) after manually stirring in $200 \mathrm{ppm}$ streptomycin to prevent bacterial growth. Samples of the mince ( $25 \mathrm{~g}$ ) were flattened out on the bottom of a $250 \mathrm{~mL}$ screw-capped Erlenmeyer flask, giving a thickness of $\sim 5 \mathrm{~mm}$, and stored on ice in darkness for up to 12 days. Samples for chemical analysis ( $1 \mathrm{~g}$ "plugs") were regularly taken out from the Erlenmeyer flask using a hollow cylinder to obtain a constant surface-to-volume ratio between different samplings. The plug was wrapped in aluminum foil and kept at $-80{ }^{\circ} \mathrm{C}$ until analysis.

\subsection{Incubation of herring by-products in different solutions}

One kilogram herring by-products were incubated with the solutions described in 2.2 (1:1 weight/volume) up to $X$ days. Two hundred ppm streptomycin was added into 

$\left(4{ }^{\circ} \mathrm{C}\right)$ in darkness for up to 7 days. Control by-products were stored at $4{ }^{\circ} \mathrm{C}$ without solution for the same amount of time as the by-products were incubated in solution. At each sampling point and for each treatment, 3 individual samples of each

by-product part (head, backbone with caudal fin and residuals) were ground together using a table top meat grinder (C/E22 N, Minerva Omega group, Italy) equipped with a plate with $4.5 \mathrm{~mm}$ holes and thereafter stirred to complete homogeneity. Samples for chemical analysis ( $\sim \mathrm{g}$ "plugs") were taken out from the by-products mince. The plug was wrapped in aluminum foil and kept at $-80^{\circ} \mathrm{C}$ until analysis.

\subsection{Direct mixing of antioxidants into minced herring by-products}

One kilogram fresh herring by-products were ground as described in 2.3 and 2.4, where after the following antioxidants were manually mixed into the by-products mice: 1) isoascorbic acid (0.2\%) + EDTA (0.044\%), 2) $0.25 \%$ Duralox MANC 3) 0.5\% Duralox MANC. Following manual stirring with 200 ppm streptomycin, all minces were stored as described in 2.3-2.4.

\subsection{Total heme pigment measurement}

Herring by-product minces (50g in total) from the different treatments was carefully placed one by one in a porcelain mortar containing liquid nitrogen. Additional liquid nitrogen was slowly added alternating with sub-portions of the $50 \mathrm{~g}$ mince as needed to completely freeze the mince. The frozen mince was pounded using a pestle to break it into smaller pieces which were then transferred to a $1 \mathrm{~L}$ stainless steel container for grinding into a fine powder. Milliliter amounts of liquid nitrogen were 
added as needed to keep the mince frozen and to facilitate grinding as well as further handling. Four grams of by-product powder was subsequently used to measure total $\mathrm{Hb}$ using the acetone-based method of Hornsey (1956).

\subsection{Analyses of lipid oxidation}

Total lipids were extracted from 1-g samples of mince using chloroform:methanol (2:1) (Cavonius \& Undeland, 2017). The chloroform phase was recovered and analyzed for peroxide value (PV) using the ferric thiocyanate method as described by Undeland et al (2002). TBA-reactive substances (TBARS) was determined according to the method of Larson et al.(2007), in the water-methanol phase recovered from the extraction described above.

\subsection{Statistics}

All experiments were done in duplicates. Total $\mathrm{Hb}$ is reported as mean \pm standard deviation (SD) $(n=2)$. An unpaired t-test was used to determine significant differences between samples regarding their content of total $\mathrm{Hb}$. To determine the effect of time, treatment and their interaction on lipid oxidation, repeated measures mixed models according to the method of Cavonius and Undeland (2017) were conducted. Data were log-transformed when residuals from models were not normally distributed. Tukey's post hoc test was used for pairwise comparisons when a significant effect was observed. Differences are regarded as significant when $p<0.05$.

\section{Results and discussion}

\section{1 $\mathrm{Hb}$ level in different parts of the by-products before and after rinsing}

$\mathrm{Hb}$ in blood is an effective catalyst for the lipid oxidation reaction, often limiting shelf 
life of fish (Richards \& Hultin, 2002). In this study, we had the hypothesis that $\mathrm{Hb}$ is particularly problematic for upgrading of fish by-products to food ingredients such as protein and oil, since veins/ capillaries are concentrated in many of the non-fillet parts of a fish (Brill \& Bushnell, 2006). To identify the by-product parts which are richest in $\mathrm{Hb}$, and thus most challenging for upgrading, we measured levels of $\mathrm{Hb}$ in different parts of herring by-products. Table 1 shows that the range of $\mathrm{Hb}$ in head, backbone, caudal fin and residuals was from 39.1 to $70.9 \mu \mathrm{mol} / \mathrm{kg}$. Previously, we measured the concentration of $\mathrm{Hb}$ to be 10.7 and $28.6 \mu \mathrm{mol} / \mathrm{kg}$ in herring fillet light and dark muscle, respectively (Chaijan \& Undeland, 2015). Thus, the difference between our previous and current studies confirmed that herring by-products contained higher concentrations of $\mathrm{Hb}$ compared with the fillet. The head contained the highest concentration of $\mathrm{Hb}(70.9 \pm 1.1 \mu \mathrm{mol} / \mathrm{kg})$ among the herring by-product parts, followed by backbone, residuals and caudal fin. These results agree with the distribution of the main blood vessels of bony fish. The main vessels in most coldblooded fish run along the backbone and radiate outward to the small vessels that supply visceral organs and muscle. Moreover, fish acquire oxygen from the water through the gills, why gills of the head part contain more blood vessels than other fish parts (Brill \& Bushnell, 2006).

In smaller fish species like herring and mackerel, active bleeding is usually not applied (Richards \& Hultin, 2002). However, some blood passively leaches out, e.g., after the filleting operation and during the pre-processing storage. Lewis et al. (1966) showed that $\mathrm{Hb}$ remained encapsulated in fish erythrocytes after rinsing blood with a 
physiological saline $(0.9 \% \mathrm{NaCl})$ washing solution. To reduce $\mathrm{Hb}$ contamination of the herring by-products, we therefore used physiological saline for rinsing. Table 1 shows that the percent of $\mathrm{Hb}$ that could be removed by rinsing with 5 volumes of $0.9 \% \mathrm{NaCl}$ was $10.3 \%, 17.9 \%, 6.6 \%$ and $18.0 \%$ in head, backbone, caudal fin, and residuals, respectively. That the rinsing operation could remove more $\mathrm{Hb} /$ blood from backbone and residuals compared with head and caudal fin, may be attributed to larger specific surface areas of backbone and residuals compared with head and caudal fin. Although the concentrations of $\mathrm{Hb}$ in the rinsed by-product group were significantly lower $(P<0.05)$ compared to the non-rinsed group for head, backbone and residuals, the amount of $\mathrm{Hb}$ removed by rinsing was relatively small. This indicated that most of the residual blood was situated in the interior of the by-products rather than on the surface, which in turn could be a results of the tap water rinsing that takes place during the commercial herring filleting operation.

\subsection{Effect of rinsing mixed herring by-products on lipid oxidation}

It was investigated whether a rinsing treatment with $0.9 \% \mathrm{NaCl}$ could stabilize herring by-products against lipid oxidation, despite the limited $\mathrm{Hb}$-removal. As a comparison, rinsing with tap water, which has an extreme osmolarity ( $0 \%$ salt), was used. PV and TBARS were used as indicators of primary and secondary lipid oxidation products, respectively. Figure $1 \mathrm{~A}$ and $1 \mathrm{~B}$ show that the PV and TBARS for the control group without rinsing were $244 \pm 13$ and $184 \pm 8 \mu \mathrm{mol} / \mathrm{kg}$, respectively, after 0.75 days, which was significantly $(P<0.05)$ higher than at day $0,71 \pm 5$ and $24 \pm 4 \mu \mathrm{mol} / \mathrm{kg}$. These results indicated that there was almost no lag phase for lipid oxidation in 
herring by-products, which confirmed hypothesis that herring by-products are even more sensitive to lipid oxidation than herring fillets (Larsson, Almgren, \& Undeland, 2007).

Although the PVs for all treatments were significantly influenced by storage time, there was no significant effect of the rinsing treatment on PVs at all sampling times during the five days of ice storage (Figure 1A). The TBARS development rates from 0.75 days to 2.75 days were ranked as follows: rinsing with $0.9 \% \mathrm{NaCl}<$ rising with tap water < no rinsing (Figure 1B). These results indicated that rinsing treatments to a small extent could prevent the formation of secondary lipid oxidation products which could be attributed to a partial $\mathrm{Hb}$ removal from the surface of the by-products (see Table 1). This observation is in agreement with the capacity of $\mathrm{Hb}$ to break down lipid hydroperoxides to e.g. carbonyls (Richards, 2010), and also agrees with previous studies with mackerel fillets (Richards, Kelleher, \& Hultin, 1998). Richards et al. (1998) used distilled water to wash mackerel fillets from rigor fish and found that washing improved the storage stability by preventing lipid oxidation, which was attributed in part to washing-induced removal of blood. However, our present results contradict our earlier study (Undeland, Ekstrand, \& Lingnert, 1998), where we found that washing of herring fillet mince with $0.05 \mathrm{M} \mathrm{NaCl}$ solution significantly promoted lipid oxidation during the subsequent frozen storage at $-20^{\circ} \mathrm{C}$. This contradiction may be explained by the difference in materials. In Undeland's study, it was a mince which was subjected to the washing process, which provided a much large surface area than that of whole fillets or by-products. This large surface area may have led to 
removal of a substantial amount of antioxidants endogenous to the muscle, e.g., a-tocopherol, ascorbic acid, GSH-px, SOD, and catalase (Undeland, Ekstrand, \& Lingnert, 1998). Sannaveerappa et al (2007) clearly showed the strong antioxidative power of the aqueous fraction ("press juice") of herring muscle, something we have also shown for other fish species (Undeland, Hultin, \& Richards, 2003). In addition, rinsing or washing fish mince has been reported to increase the ratio between pro-oxidants and phospholipids (Undeland, Ekstrand, \& Lingnert, 1998), which may be another reason why washing promoted lipid oxidation in herring mince, but not in intact herring by-products parts.

Furthermore, between 0.75 day and 2.75 days, rinsing with physiological saline showed significantly lower $(P<0.05)$ TBARS values compared with tap water rinsing (Figure 1B). This may be a result of the extreme osmolarity of tap water, which could induce erythrocyte lysis, thereby releasing $\mathrm{Hb}$ allowing their contact with the lipids. In contrast, physiological osmolarity $(0.9 \% \mathrm{NaCl})$ would keep the $\mathrm{Hb}$ within the erythrocytes (Lewis \& Ferguson, 1966), thereby minimizing $\mathrm{Hb}$ interaction with by-product lipids and preventing lipid oxidation.

To improve the lipid-stabilizing effect of rinsing during subsequent storage of by-products, we used antioxidants in combination with tap water and $0.9 \% \mathrm{NaCl}$ solution as the rinsing media. In this case, the rinsing was regarded more as a dipping instead of a wash, as it was meant to cover the surface and outer layer of the by-products with antioxidants. Dipping with antioxidants was earlier used to stabilize horse mackerel fillets against lipid oxidation (Pazos, Alonso, Fernández-Bolaños, 
Torres, \& Medina, 2006). Figure 2 shows that the lipid oxidation rate was lower when dipping in isoascorbic acid + EDTA solution compared with no dipping, based on PV and TBARS values from 0 to 2.75 days. However, there were no significant differences for PV and TBARS values between isoascorbic acid + EDTA dipping and no dipping after 4.75 days. These results indicated that isoascorbic acid + EDTA provided a lower lipid oxidation rate in the initial storage period from 0 to 2.75 days, and then a higher lipid oxidation rate from 2.75 days to 4.75 days. This phenomenon may be attributed to the biphasic effect (anti- and pro-oxidant) of isoascorbic acid. Similarly, Richards et al. (2004) reported that ascorbate $(2.2 \mathrm{mM})$ presented both an antioxidant and a pro-oxidant effect in a washed cod mince model enriched with trout $\mathrm{Hb}$. The inhibition provided by ascorbate could be attributed to the ability to scavenge free radicals and reduce hypervalent forms of $\mathrm{Hb}$ (Kröger-Ohlsen \& Skibsted, 1997). Conversely, the shift of ascorbate from an antioxidant to a pro-oxidant could be due to a break-down of accumulated lipid hydroperoxides to reactive lipid radicals capable of propagating lipid oxidation (S. H. Lee, Oe, \& Blair, 2001). The same could be provided by the capacity of ascorbate to reduce low-molecular-weight iron to its ferrous, and more pro-oxidant form (Yamamoto, Takahashi, \& Niki, 1987). The shift from anti- to pro-oxidant action is evident especially at low ascorbate concentrations; according to Ramanathan and Das at $<280 \mu \mathrm{mol} / \mathrm{kg}$ )(Ramanathan \& Das, 1992). We also added Duralox MANC, a commercial antioxidant mixture, to the dipping medium. Figure 2A clearly shows that all PVs for MANC treated by-products were significantly lower $(P<0.05)$ compared with isoascorbic acid + EDTA and control (no rinsing) from 
0.75 to 4.75 days. Also with Duralox MANC treatment, the PVs did not change from time zero in three sampling points $0.75,2.75$ and 4.75 days. There was a slight increase in PV from 4.75 to 7.75 days and a rapid increase was observed after 7.75 days. These results indicated the Duralox MANC effectively inhibited production of primary lipid oxidation products up to 7.75 days. Figure 2B shows that Duralox MANC also completely inhibited formation of secondary lipid oxidation products (TBARS). All observed TBARS were between 16 and $32 \mu \mathrm{mol} / \mathrm{kg}$ from 0 to 12 days, and there were no significant differences between any of the sampling points. Duralox MANC is a mixture of rosemary extract, ascorbic acid, tocopherols and citric acid. Rosemary extract is the principal component on a weight basis and it may be key to inhibition of lipid oxidation of the by-products. Vareltzis et al. (1997) performed dipping of mackerel (Trachurus trachurus) fillets in a water solution containing $800 \mathrm{mg}$ rosemary extract/L where after the fillets were vacuum-packaged. The rosemary extract significantly retarded oxidation of the fillets during subsequent frozen storage. The mechanisms involved in retarding oxidation most likely include free radical scavenging and possibly inactivation of low molecular weight metals by chelation (Richards, 2010). Besides the rosemary extract, the other antioxidants in Duralox MANC (ascorbic acid, tocopherols and citric acid) are believed to provide important synergies with the polyphenols of the rosemary extract. Wada et al (1992) showed that a mixture of rosemary extract and $\alpha$-tocopherol $(0.02 \%+0.05 \%)$ had the highest antioxidant activity in frozen fish muscle and delayed the onset of oxidation five days longer than either rosemary extract or $\alpha$-tocopherol alone. Similarly, Hraš et al (2000) 
reported that, when combined with citric acid, rosemary extract showed an additive antioxidative effect compared with rosemary extract alone in sunflower oil stored at $60^{\circ} \mathrm{C}$.

It was interesting to note that Duralox MANC treatment did not exert as strong inhibitory effect on formation of primary lipid oxidation products (PV) from 7.75 to 12 days, as it did on generation of secondary lipid oxidation products (TBARS) in this period. These results may be attributed to partial breakdown of the antioxidants that inhibit formation of primary lipid oxidation products, while those antioxidants that could inhibit secondary lipid oxidation products formation remained effective. On the basis of the capacity to inhibit oxidation reactions, antioxidants can be classed into primary and secondary antioxidants (Berdahl, Nahas, \& Barren, 2010). Primary antioxidants are substances that disrupt the free radical chain propagation process to reduce the formation of hydroperoxides; secondary antioxidants are substances that react with hydroperoxides, converting them to more stable, non-radical products (Reische, Lillard, \& Eitenmiller, 2002). This could be for instance tocopherols and tocotrienols. In this sub-study, the primary antioxidants may begin to break down after 7.75 days, which could result in a rapid increase of the PV. However, the secondary antioxidants such as citric acid could still exert their antioxidative effects to convert hydroperoxides to more stable, non-radical products, explaining why the TBARS did not increase significantly during the 12 days of ice storage. Another possibility is that Duralox MANC inactivated the ability of $\mathrm{Hb}$ to break down primary oxidation products to carbonyls and new radicals, which is one of the major pro-oxidative roles of heme-proteins (Richards, 2010). 


\subsection{Incubation of herring by-products in water or physiological salt}

As a strategy to avoid direct contact between by-products and air during pre-processing storage, we evaluated an incubation of the herring by-products in tap water or $0.9 \% \mathrm{NaCl}$ solution at $4{ }^{\circ} \mathrm{C}$ for up to 7 days. Figure 3 shows that there was no significant difference in the lipid oxidation rates between tap water and $0.9 \% \mathrm{NaCl}$ treatments. However, a significantly lower lipid oxidation rate was observed in incubated by-products compared with controls stored in air based on PV and TBARS values. Similarly, Losada et al. (2006) reported that storage of sardine (Sardina pilchardus) in an ice slurry (40\% ice/60\% water) resulted in lower oxidation values (TBARS, peroxide value) compared with those stored in flake ice. Ortiz et al. (2008) used flow ice (prepared from filtered sea water) to store rainbow trout (On. mykiss) which increased shelf life from 8 days to 13 and 16 days compared with those stored in normal ice.

To make the incubation solutions even more effective, different antioxidant additives were used in one of our sub-studies. Figure 4 shows that all incubation treatments had a lower lipid oxidation rate based on PV and TBARS values compared with controls stored in air, which agrees with the results of Figure 3. According to the PV and TBARS results, the effect of incubation with different additives was stronger than just incubation with tap water or $0.9 \% \mathrm{NaCl}$. Besides the reduced contact between oxygen and lipids (Richards, Kelleher, \& Hultin, 1998), this could be attributed to one or both of the following two reasons: i) the incubation solution could remove or dilute a part of the $\mathrm{Hb}$ from the by-products and ii) the incubation could efficiently 
cover the surface of the by-products with the tested antioxidants. Figure 4 shows that the Duralox MANC treatment had the strongest inhibiting ability for lipid oxidation, which confirmed this hypothesis. Similarly, Quitral et al.(2009) showed a significant decrease in lipid oxidation when Chilean jack mackerel (Trachurus murphyi) was stored in an ice-water system including rosemary extracts in refrigerated room $\left(4{ }^{\circ} \mathrm{C}\right)$ compared to the same system without rosemary extract. Figure 4 also shows that there was no significant difference in lipid oxidation between $\mathrm{pH} 6.5$ and $\mathrm{pH} 7.5$ incubation PBS solution. However, our previous study showed that a higher $\mathrm{pH}(\mathrm{pH}$ 7.2) prevented lipid oxidation in a washed cod mince model system compared to $\mathrm{pH}$ 6.0, as the latter stimulate formation of deoxyhemoglobin and methemoglobin (Undeland, Kristinsson, \& Hultin, 2004). This contradiction may be explained by the difference in the actual systems studied. In this sub-study, the $\mathrm{pH}$ was adjusted only in the solution which were incubated with the by-products, while in Undeland's study, the entire washed cod mince model was $\mathrm{pH}$-adjusted. Moreover, Figure 4 shows that there was no significant difference in lipid oxidation between $1 \%$ and $0.5 \%$ of Duralox MANC, which shows that a plateau was reached, which is indeed positive from an economic perspective if the present antioxidant strategy would be implemented in indystry.

\subsection{Direct add of antioxidants into minced herring by-products}

The above two strategies (rinsing and incubation) were proven promising ways to stabilize by-products against oxidation if they are to be kept intact prior to further processing. However, they never indicated which exact level of the added 
antioxidants that reached into the herring tissue, and thus, which in situ levels there were needed to prevent oxidation. In this sub-study, we therefore tried to confirm which concentration of isoascorbic acid + EDTA and Duralox MANC, respectively,

which would be needed to efficiency inhibit lipid oxidation during ice storage following direct addition into by-product minces, which could be a ready-to-process material for further value adding operations. Figure $5 \mathrm{~A}$ and $5 \mathrm{~B}$ show that the PV and TBARS values rapidly increased from zero-time and arrived at $737 \pm 32$ and $216 \pm 25$ $\mu \mathrm{mol} / \mathrm{kg}$, respectively, after 2 days without any addition of antioxidants. However, all antioxidant treatments provided significantly lower PV and TBARS values after 2 days compared to the control. Furthermore, the lag phases for PV were 1, 2 and $>8$ days for isoascorbic acid (0.2\%) + EDTA (0.044\%), 0.25\% MANC and 0.5\% MANC, respectively (Figure 5A). The corresponding lag phases for TBARS were 2, 4 and $>8$ days (Figure 5B). These results indicated the ability of the antioxidant ranked them as: $0.5 \%$ MANC $>>0.25 \%$ MANC $>$ isoascorbic acid $(0.2 \%)+$ EDTA $(0.044 \%)$. These results show that Duralox MANC is needed if by-product minces should be stored $>4$ days close to $0^{\circ} \mathrm{C}$.

\section{Conclusions}

Herring by-products have been successfully stabilized by three different antioxidant strategies; rinsing and incubation of the intact by-products, or direct addition into the by-products after mincing. The effects of the treatments were in some cases remarkable; shelf life went from $<1$ day to $>12$ days, and Duralox MANC was in all sub-studies the most effective antioxidant. Given it simplicity, the rinsing treatment was particularly promising. Overall, our study paves the way for an extended window 
of time during which it is possible to upgrade herring by-products to food ingredients, despite the fact that they per se are a highly sensitive system when it comes to lipid oxidation. This would be a more sound and holistic utilization of the valuable herring biomass.

\section{Acknowledgement}

This work was supported by VINNOVA (Project No. 2017-03155). We wish to thank Mursalin Sajib for help with grinding of herring by-products and Lin Shi for help with statistical analyses.

\section{Reference}

Abdollahi, M., \& Undeland, I. (2019). Physicochemical and gel-forming properties of protein isolated from salmon, cod and herring by-products using the pH-shift method. LWT, 101, 678-684.

Alexandratos, N., \& Bruinsma, J. (2012). World agriculture towards 2030/2050: the 2012 revision. In): ESA Working paper FAO, Rome.

Berdahl, D., Nahas, R., \& Barren, J. (2010). Synthetic and natural antioxidant additives in food stabilization: current applications and future research. In Oxidation in foods and beverages and antioxidant applications, (pp. 272-320): Elsevier.

Brill, R., \& Bushnell, P. (2006). Effects of open-and closed-system temperature changes on blood O 2-binding characteristics of Atlantic bluefin tuna (Thunnus thynnus). Fish Physiology and Biochemistry, 32(4), 283-294.

Cavonius, L. R., \& Undeland, I. (2017). Glazing herring (Clupea harengus) fillets with herring muscle press juice: effect on lipid oxidation development during frozen storage. International journal of food science \& technology, 52(5), 1229-1237. 

protein in fish muscle. Food chemistry, 173, 1133-1141.

FAO. (2014). The State of World Fisheries and Aquaculture. Agriculture Organization of the United Nations. Fisheries Department (Vol. 3): Food \& Agriculture Org.

Hornsey, H. (1956). The colour of cooked cured pork. I. - Estimation of the Nitric oxide-Haem Pigments. Journal of the Science of Food and Agriculture, 7(8), 534-540.

Hraš, A. R., Hadolin, M., Knez, Ž., \& Bauman, D. (2000). Comparison of antioxidative and synergistic effects of rosemary extract with $\alpha$-tocopherol, ascorbyl palmitate and citric acid in sunflower oil. Food chemistry, 71(2), 229-233.

Hultin, H. O., \& Kelleher, S. D. (1999). Process for isolating a protein composition from a muscle source and protein composition. In): Google Patents.

Kröger-Ohlsen, M., \& Skibsted, L. H. (1997). Kinetics and mechanism of reduction of ferrylmyoglobin by ascorbate and D-isoascorbate. Journal of Agricultural and Food chemistry, 45(3), 668-676.

Larsson, K., Almgren, A., \& Undeland, I. (2007). Hemoglobin-mediated lipid oxidation and compositional characteristics of washed fish mince model systems made from cod (Gadus morhua), herring (Clupea harengus), and salmon (Salmo salar) muscle. Journal of Agricultural and Food chemistry, 55(22), 9027-9035.

Larsson, K., \& Undeland, I. (2010). Effect of caffeic acid on haemoglobin-mediated lipid and protein oxidation in washed cod mince during ice and frozen storage. Journal of the Science of Food and Agriculture, 90(14), 2531-2540.

Lee, C., Krueger, C. G., Reed, J. D., \& Richards, M. P. (2006). Inhibition of hemoglobin-mediated lipid oxidation in washed fish muscle by cranberry components. Food chemistry, 99(3), 591-599. 
Lee, S. H., Oe, T., \& Blair, I. A. (2001). Vitamin C-induced decomposition of lipid hydroperoxides to endogenous genotoxins. Science, 292(5524), 2083-2086.

Lewis, J. H., \& Ferguson, E. E. (1966). Osmotic fragility of premammalian erythrocytes. Comparative biochemistry and physiology, 18(3), 589-595.

Liaset, B., Lied, E., Espe, M. J. J. o. t. S. o. F., \& Agriculture. (2000). Enzymatic hydrolysis of by-products from the fish-filleting industry; chemical characterisation and nutritional evaluation. 80(5), 581-589.

Losada, V., Barros-Velázquez, J., Gallardo, J. M., \& Aubourg, S. P. (2006). Effect of previous slurry ice treatment on the quality of cooked sardine (Sardina pilchardus). European Food Research and Technology, 224(2), 193-198.

Ortiz, J., Palma, Ó., González, N., \& Aubourg, S. P. (2008). Lipid damage in farmed rainbow trout (Oncorhynchus mykiss) after slaughtering and chilled storage. European journal of lipid science and technology, 110(12), 1127-1135.

Pazos, M., Alonso, A., Fernández-Bolaños, J., Torres, J. L., \& Medina, I. (2006). Physicochemical properties of natural phenolics from grapes and olive oil byproducts and their antioxidant activity in frozen horse mackerel fillets. Journal of Agricultural and Food chemistry, 54(2), 366-373.

Quitral, V., Donoso, M. L., Ortiz, J., Herrera, M. V., Araya, H., \& Aubourg, S. P. (2009). Chemical changes during the chilled storage of Chilean jack mackerel (Trachurus murphyi): Effect of a plant-extract icing system. LWT-Food Science and Technology, 42(8), 1450-1454.

Ramanathan, L., \& Das, N. (1992). Studies on the control of lipid oxidation in ground fish by some polyphenolic natural products. Journal of Agricultural and Food chemistry, 40(1), 17-21. 

Biotechnology; Akoh, CC, Min, DB, Eds. In): CRC Press: New York, NY, USA.

Richards, M. P. (2010). Heme proteins and oxidation in fresh and processed meats. In Oxidation in foods and beverages and antioxidant applications, (pp. 76-104): Elsevier.

Richards, M. P., \& Hultin, H. O. (2002). Contributions of blood and blood components to lipid oxidation in fish muscle. Journal of Agricultural and Food chemistry, 50(3), 555-564.

Richards, M. P., Kelleher, S. D., \& Hultin, H. O. (1998). Effect of washing with or without antioxidants on quality retention of mackerel fillets during refrigerated and frozen storage. Journal of Agricultural and Food chemistry, 46(10), 4363-4371.

Richards, M. P., \& Li, R. (2004). Effects of released iron, lipid peroxides, and ascorbate in trout hemoglobin-mediated lipid oxidation of washed cod muscle. Journal of Agricultural and Food chemistry, 52(13), 4323-4329.

Rustad, T. (2003). Utilisation of marine by-products. Electronic Journal of Environmental, Agricultural and Food Chemistry, 2(4), 458-463.

Sánchez-Alonso, I., Borderías, J., Larsson, K., \& Undeland, I. (2007). Inhibition of hemoglobin-mediated oxidation of regular and lipid-fortified washed cod mince by a white grape dietary fiber. Journal of Agricultural and Food chemistry, 55(13), 5299-5305.

Sannaveerappa, T., Carlsson, N.-G., Sandberg, A.-S., \& Undeland, I. (2007). Antioxidative properties of press juice from herring (Clupea harengus) against hemoglobin $(\mathrm{Hb})$ mediated oxidation of washed cod mince. Journal of Agricultural and Food chemistry, 55(23), 9581-9591.

Undeland, I., Ekstrand, B., \& Lingnert, H. (1998). Lipid oxidation in minced herring (Clupea harengus) during frozen storage. Effect of washing and precooking. Journal of Agricultural and Food 
chemistry, 46(6), 2319-2328. hemoglobin-mediated lipid oxidation in washed minced cod muscle. Journal of Agricultural and Food chemistry, 50(23), 6847-6853.

Undeland, I., Hultin, H. O., \& Richards, M. P. (2003). Aqueous extracts from some muscles inhibit hemoglobin-mediated oxidation of cod muscle membrane lipids. Journal of Agricultural and Food chemistry, 51(10), 3111-3119.

Undeland, I., Kristinsson, H. G., \& Hultin, H. O. (2004). Hemoglobin-mediated oxidation of washed minced cod muscle phospholipids: Effect of $\mathrm{pH}$ and hemoglobin source. Journal of Agricultural and Food chemistry, 52(14), 4444-4451.

Wada, S., \& Fang, X. (1992). The synergistic antioxidant effect of rosemary extract and $\alpha$-tocopherol in sardine oil model system and frozen-crushed fish meat. Journal of Food Processing and Preservation, 16(4), 263-274.

Vareltzis, K., Koufidis, D., Gavriilidou, E., Papavergou, E., \& Vasiliadou, S. (1997). Effectiveness of a natural Rosemary (Rosmarinus officinalis) extract on the stability of filleted and minced fish during frozen storage. Zeitschrift für Lebensmitteluntersuchung und-Forschung A, 205(2), 93-96.

Vareltzis, P. K., \& Undeland, I. (2012). Protein isolation from blue mussels (Mytilus edulis) using an acid and alkaline solubilisation technique-process characteristics and functionality of the isolates. Journal of the Science of Food and Agriculture, 92(15), 3055-3064.

Yamamoto, K., Takahashi, M., \& Niki, E. (1987). Role of iron and ascorbic acid in the oxidation of methyl linoleate micelles. Chemistry Letters, 16(6), 1149-1152. 
Zhong, S., Liu, S., Cao, J., Chen, S., Wang, W., \& Qin, X. J. J. o. A. F. P. T. (2016). Fish protein isolates recovered from silver carp (Hypophthalmichthys molitrix) by-products using alkaline $\mathrm{pH}$ solubilization and precipitation. 25(3), 400-413. 


\section{Figure Captions}

Figure 1. Lipid oxidation measured as (A) lipid hydroperoxides and (B) TBA-reactive substances (TBARS) during ice storage of herring by-product mince that had been The ratio of herring by-products to solution was 1:5 weight/volume.

Figure 2. Lipid oxidation measured as (A) lipid hydroperoxides and (B) TBA-reactive substances (TBARS) during ice storage of herring by-product mince that had been pre-treated by rinsing the intact by-products with antioxidant solutions. 1). 5\% Duralox MANC-213 in tap water; 2) Isoascorbic acid (0.2\%) + EDTA (0.044\%) in 0.9\% $\mathrm{NaCl}$ solution, 3 ) isoascorbic acid $(0.2 \%)+$ EDTA $(0.044 \%)$ in tap water. The ratio of herring by-products to solution is 1:5 weight/volume.

Figure 3. Lipid oxidation measured as (A) lipid hydroperoxides and (B) TBA-reactive substances (TBARS) during storage in a cold room $\left(4^{\circ} \mathrm{C}\right)$ of herring by-products that were incubated with tap water, and $0.9 \%$ salt solutions. The ratio of herring by-products to solution is 1:1 weight/volume.

Figure 4. Lipid oxidation measured as (A) lipid hydroperoxides and (B) TBA-reactive substances (TBARS) during storage in cold room $\left(4{ }^{\circ} \mathrm{C}\right)$ of herring by-products that were incubated with different solutions. The ratio of herring by-products to solution is $1: 1$ weight/volume.

Figure 5. Lipid oxidation measured as (A) lipid hydroperoxides and (B) TBA-reactive substances (TBARS) during ice storage of minced herring by-products which were fortified with antioxidants: 1) Isoascorbic acid (0.2\%) + EDTA (0.044\%), 2) $0.25 \%$ Duralox MANC 3) 0.5\% Duralox MANC. 
Table 1 The effect of $0.9 \% \mathrm{NaCl}$ rinsing $^{\mathrm{A}}$ on total $\mathrm{Hb}_{\text {level }}{ }^{\mathrm{B}}$ in different parts of herring by-products

\begin{tabular}{lllll}
\hline Treatment & Head $^{\mathrm{C}}$ & Backbone & Caudal fin & Residuals \\
\hline No rinsing & $70.9 \pm 1.1^{\mathrm{a}}$ & $42.8 \pm 0.3^{\mathrm{a}}$ & $39.1 \pm 1.8^{\mathrm{a}}$ & $40.6 \pm 1.1^{\mathrm{a}}$ \\
Rinsing & $63.6 \pm 1.5^{\mathrm{b}}$ & $35.1 \pm 0.8^{\mathrm{b}}$ & $36.47 \pm 1.3^{\mathrm{a}}$ & $33.3 \pm 0.5^{\mathrm{b}}$
\end{tabular}

$\overline{{ }^{A}}$ The ratio was 5:1 for $0.9 \% \mathrm{NaCl}$ solution/by-products (volume/weight). The process of rinsing was 20 minutes in $4^{\circ} \mathrm{C}$ under gentle stirring. ${ }^{\mathrm{B}}$ The unit of total $\mathrm{Hb}$ is $\mu \mathrm{mol} / \mathrm{kg}$ herring by-products. ${ }^{C}$ Data are means \pm standard deviations $(n=2)$. Means bearing different designations $(a, b)$ in a column differ significantly $(P<0.05)$. 
Figure 1.
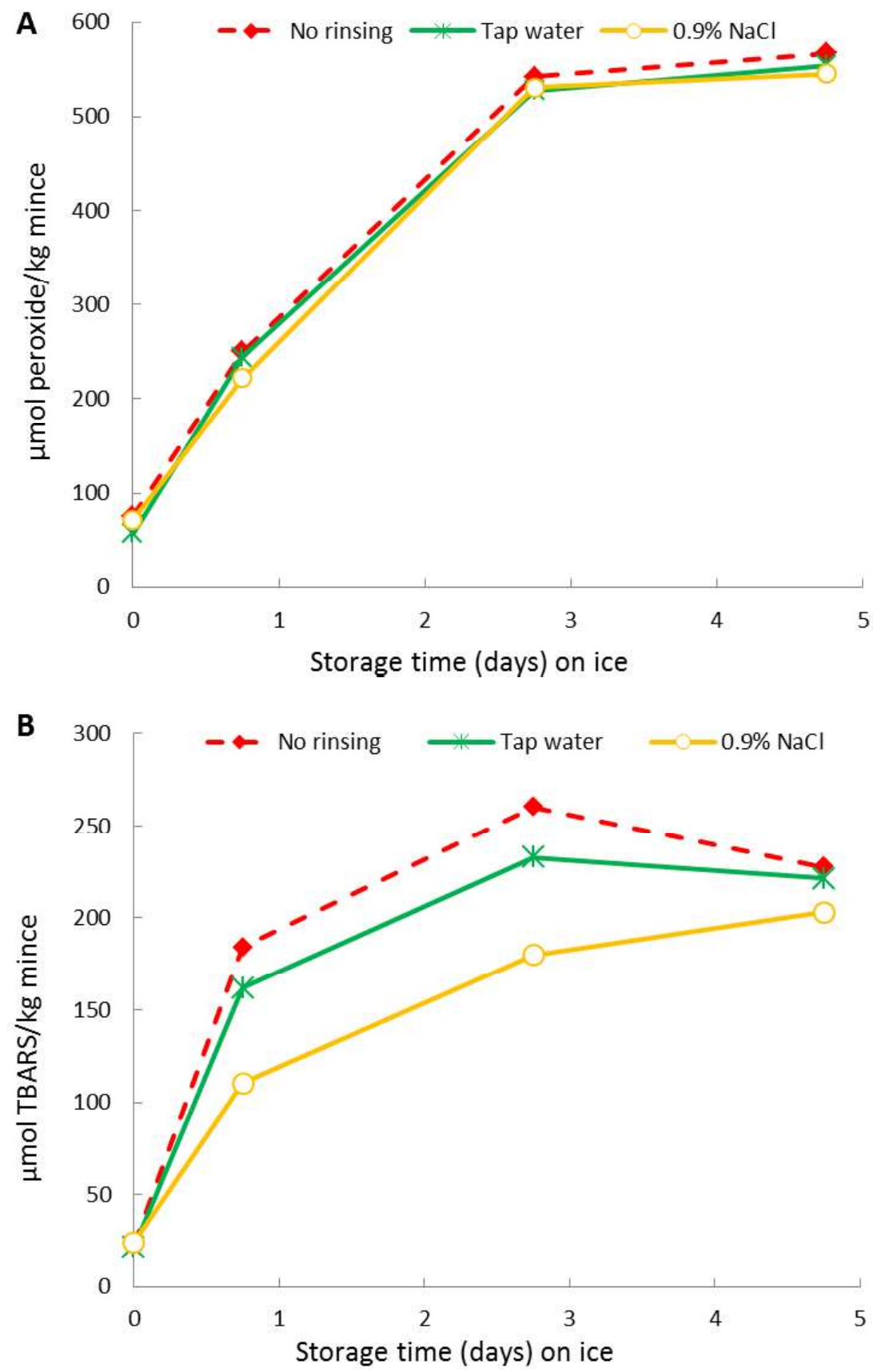
Figure 2.
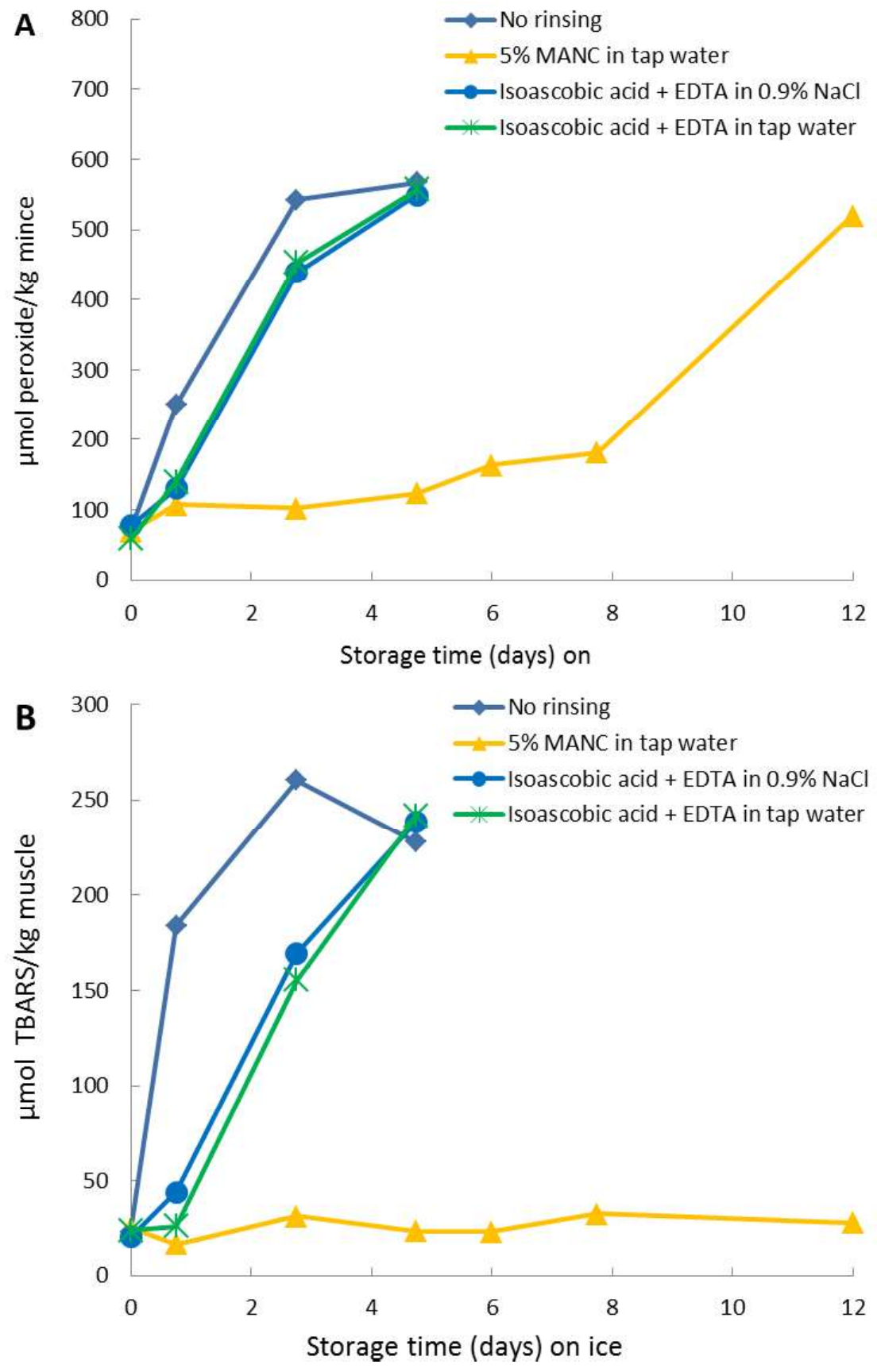
Figure 3.
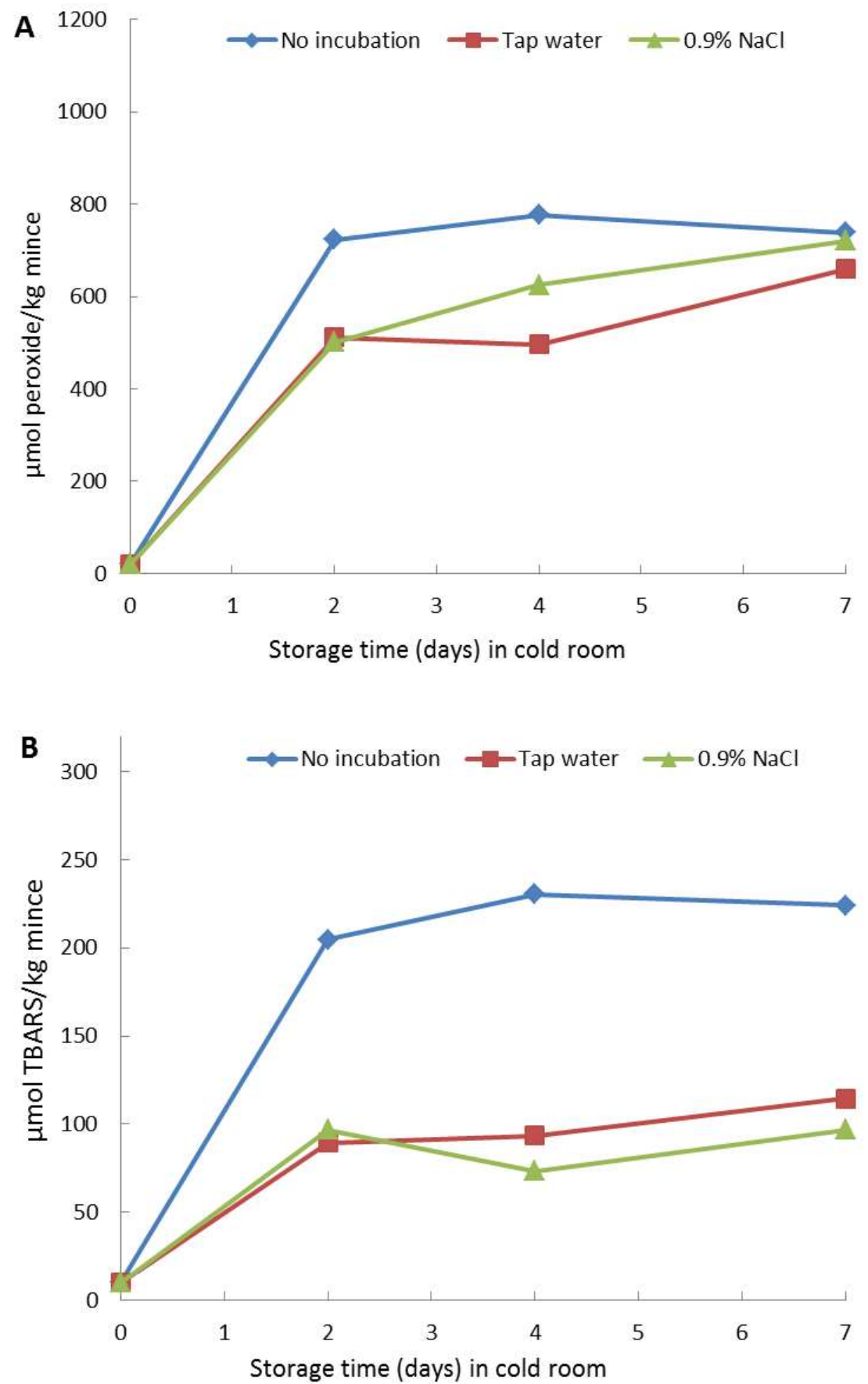
Figure 4.

Figure 5.
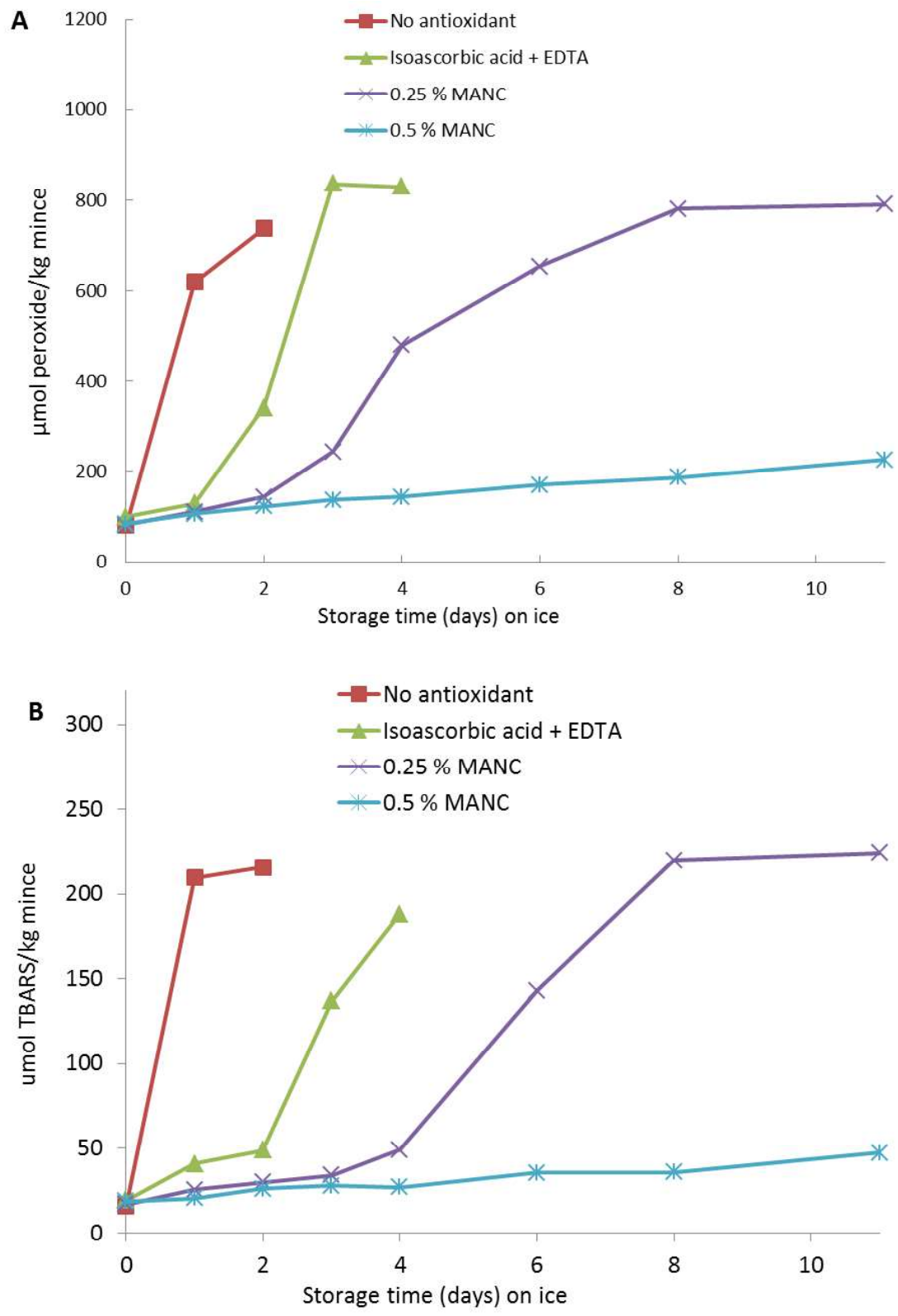